\title{
Persepsi Pemustaka dari Latar Belakang Sosial yang Berbeda terhadap Fungsi Perpustakaan (Studi di Perpustakaan Kota Yogyakarta)
}

\author{
Rizki Nurislaminingsih* dan Partini** \\ email: rizkinurvega@gmail.com
}

\begin{abstract}
Nowadays, the existence of technology in the middle of the society does not only give the abundant information, but also causes confusion and boredom in searching for the information. Such situation also has influenced the society's demand with different social stratifications in their easiness of accessing the information. Yogyakarta City Library, which in fact is an information center for the whole society layers, is expected to be able to be a bridge for the impacts of technology existence in information searching process. This study aimed at finding out the influence of social environment in building perceptions towards the library functions and how the library functions were viewed by readers with different social stratifications.

The method used in this study was the combination of quantitative and qualitative approaches with Concurrent Triangulation design, in which two approaches were used simultaneously. However, data gathering and data analysis processes were done separately. The respondents were fifty users selected through random sampling. The in-depth interview was done towards ten informants.

The result of the study indicated that social environment was not only influential in building the society's perceptions towards the library functions, but also motivated the readers to visit the library. Besides, it was found out that there was the change regarding to the society's perceptions with different social backgrounds towards the library functions. Recently, a library has not only been viewed as a book storage or solely an information provider, but has also been viewed as a rare collections preserver, an amusement place, simply a spot for hanging out with friends, and a positive game facility among children and parents. In addition, a library has also been viewed as a successor of the education missions and as a medium for channeling the society's talent and creativity.
\end{abstract}

Keywords: Perception, Social Environment, Social Stratification, Library Functions, Concurrent Triangulation.

*) Dosen Kontrak Jurusan Ilmu Perpustakaan Undip

**) Dosen Jurusan Sosiologi UGM

\section{A. PENDAHULUAN}

\section{Latar Belakang}

"Information is everywhere and in huge amounts. How much is there (can we find out)? Where does it come from? What can we do to find out what it's worth while providing some level of organization and control?" (Davis and Shaw, 2011: 1). Berdasarkan kutipan tersebut dapat kita ketahui gambaran informasi yang terus berkembang dan tak terhitung lagi jumlahnya. Peningkatan informasi semakin terasa pesat dengan munculnya teknologi yang kian memberi kemudahan bagi masyarakat untuk mencari, menemukan, menyebarluaskan bahkan menciptakan informasi. Bila diistilahkan, cukup dengan satu perangkat teknologi yang tersambung dengan internet, segala macam informasi tersaji dengan cepat.

Seiring berjalannya waktu, "ledakan informasi" menimbulkan kebingungan dalam diri masyarakat akan banyaknya pilihan informasi. Lambat laun masyarakat juga mulai merasa jenuh dengan informasi yang tersedia dalam perangkat teknologi. Jika sudah demikian, cepat atau lambat masyarakat mulai menuntut suguhan informasi yang beragam jenisnya dan dikemas secara unik. Menjawab tuntutan tersebut, saat ini kita melihat 
perpustakaan mulai berinovasi melalui layanan hibrida, yaitu gabungan layanan manual dan bantuan perangkat teknologi, seperti yang dikemukakan Borgman (2003: 87) dalam Suwarno (2010: 29-30) "Hybrid libraries are designed to brings of technologies from different sources together in the context of a working library, and also to begin to explore integrated systems and services in both the electronic and print environments".

Duet dahsyat antara layanan konvensional dengan perangkat teknologi dapat memberikan manfaat yang beragam bagi masyarakat dan juga mampu merubah kesan perpustakaan agar tidak identik dengan gudang buku. Namun demikian, pada kenyataannya perpustakaan masih dipandang sebelah mata oleh masyarakat. Sudah bukan rahasia lagi bahwa perpustakaan hanya dimaknai sebagai gudang buku yang dingin dan kaku, meskipun ada sebagian masyarakat lain yang melihat perpustakaan dari sisi manfaat seperti lembaga penyedia ilmu, sarana belajar di luar bangku sekolah hingga tempat bermain bersama teman.

Perpustakaan yang telah melakukan gebrakan dalam sajian layanan informasi yakni Perpustakaan Kota Yogyakarta dengan memberikan layanan yang beragam jenisnya, misalnya layanan sirkulasi, referensi, perpustakaan keliling, diskusi buku, sanggar menulis, mendongeng bersama, liburan di perpustakaan kota dan berbagi buku dengan sesama.

Perbaikan layanan tersebut diharapkan dapat memberikan manfaat layanan yang tidak sebatas pada menyuguhkan buku atau interaksi antara petugas dengan pengunjung yang membosankan, tetapi juga dapat menjadi sarana hiburan yang mendidik bagi pemustaka. Hal ini sangat dibutuhkan terutama pada kondisi masyarakat dari berbagai latar belakang sosial berbeda.

Berdasarkan situs internet Perpustakaan Kota Yogyakarta, dapat diketahui pemustaka terdiri dari berbagai kalangan masyarakat, mulai dari pelajar, mahasiswa, ibu rumah tangga hingga pegawai. Selain itu, kondisi pemustaka yang memiliki beragam latar belakang sosial, seperti pekerjaan dan pendidikan akan menimbulkan beragam kebutuhan yang tentu saja berdampak pada perbedaan tuntutan akan jenis dan sumber informasi. Manfaat perpustakaan bagi masyarakat dapat diketahui dari persepsi pemustaka terhadap fungsi perpustakaan.

Berdasarkan latar belakang di atas, maka dapat dibuat rumusan masalah sebagai berikut: 1) Faktor apa saja yang berpengaruh dalam membentuk persepsi terhadap fungsi perpustakaan ? dan 2) Bagaimana persepsi pemustaka di Perpustakaan Kota Yogyakarta terhadap fungsi perpustakaan?

\section{Kerangka Berpikir}

Konsep awal dalam penelitian ini untuk mengetahui pandangan masyarakat terhadap fungsi perpustakaan. Kelengkapan persepsi tersebut dapat diketahui berdasarkan lingkungan sosial dan stratifikasi sosial. Peran lingkungan sosial yang membentuk persepsi dilakukan oleh orang-orang terdekat, seperti keluarga, teman dan pendidik. Cara orang tua mendidik anak agar mencintai perpustakaan atau tidak akan mempengaruhi pandangan sang anak terhadap perpustakaan. Ajakan teman serta saran dari guru untuk berkunjung ke perpustakaan juga akan membentuk persepsi seorang anak pada fungsi perpustakaan. Selain itu, seseorang dengan pekerjaan yang berbeda mungkin akan menghasilkan persepsi yang berbeda. Begitupula dengan perbedaan latar belakang pendidikan. Berikut gambar alur pemikiran penelitian:

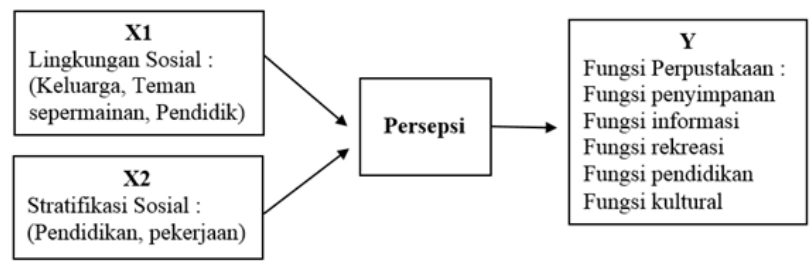

Gambar 2.1 Bagan Kerangka Alur Pemikiran Penelitaan

\section{B. TINJAUAN PUSTAKA}

1. Persepsi

Menurut Leavitt (1978) dalam Sobur (2013: 445) persepsi dalam arti sempit ialah bagaimana cara seseorang memandang sesuatu. Sedangkan dalam arti luas adalah bagaimana seseorang mengartikan sesuatu. Hal senada juga disampaikan oleh Thoha (1995: 123) bahwa kunci untuk memahami persepsi terletak pada pengenalan bahwa persepsi merupakan suatu penafsiran yang unik terhadap situasi, dan bukannya suatu pencatatan yang benar terhadap situasi. 


\section{Lingkungan Sosial}

Lingkungan diartikan sebagai berbagai pihak luar (diluar diri individu) yang mempengaruhi individu tersebut. Lingkungan terdiri dari lingkungan sosial (elemen manusia yang melingkupi individu) dan lingkungan alam yang berupa unsur bukan manusia yang ada di sekitar individu tersebut (Hunt dan Colander, 1996: 138). Schaefer (2013: 79) mengungkapkan lingkungan sosial juga mempengaruhi manusia dalam berkeyakinan, mempersepsi, mengungkapkan perasaan, menilai, hingga memunculkan reaksi terhadap rangsangan. Soekanto (1999: 494-501) menjelaskan bahwa lingkungan sosial seseorang terdiri dari keluarga, kelompok sepermainan dan kelompok pendidik atau guru.

\section{Stratifikasi Sosial}

Menurut Sunarto (1993: 105) stratifikasi sosial adalah pembedaan anggota masyarakat berdasarkan status yang dimilikinya dalam lingkungan sosial. Berikut beberapa stratifikasi sosial yang dikutip dari buku Pengantar Sosiologi (Sunarto, 1993: 106-107) yakni stratifikasi usia, jenis kelamin, pendidikan dan pekerjaan. Menindaklanjuti penjelasan tersebut, dapat diketahui bahwa objek dalam penelitian ini berupa perpustakaan yang dipersepsi dari segi fungsi.

\section{Fungsi Perpustakaan}

Sulistyo-Basuki (1991: 27-29) menuturkan bahwa eksistensi perpustakaan dalam masyarakat harus tetap dijaga karena perpustakaan mempunyai fungsi yang berkaitan dengan kepentingan masyarakat, fungsi tersebut antara lain fungsi penyimpan hasil karya manusia (berupa buku, majalah serta karya rekam) fungsi informasi (sebagai penyaji informasi), fungsi rekreasi (manfaat hiburan sekaligus mendidik), fungsi pendidikan (tempat belajar di luar bangku pendidikan) dan fungsi kultural (mengembangkan apresiasi budaya).

\section{Penelitian Sebelumnya}

Penelitian ini bertujuan untuk mengetahui bagaimana Persepsi Pemustaka di Perpustakaan Kota Yogyakarta Terhadap Fungsi Perpustakaan. Perbedaan penelitian ini dengan penelitian sebelumnya terletak pada latar belakang responden yang diteliti, metode pengumpulan data dan pemilihan teori fungsi perpustakaan. Jika pada penelitian Fuegi et al. (2011) responden berasal dari masyarakat umum (pemustaka, nonpemustaka, pegawai hingga pejabat di instansi tertentu), penelitian Smith (2008) memilih pustakawan dan Rahmawati (2008) memilih masyarakat dari dua daerah (Bumijo dan Sidorejo) sebagai responden, maka responden pada penelitian ini yakni pemustaka di Perpustakaan Kota Yogyakarta.

Perbedaan lain terletak pada pemilihan metodologi penelitian. Jika pada penelitian Fuegi et al. (2011) menggunakan kualitatif dan kuantitatif, serta penelitian Smith (2008) menggunakan focus group discussion dan Rahmawati (2008) menggunakan survei untuk uji hipotesis, maka pada penelitian ini menggunakan desain Concurent Triangulation. Perbedaan ketiga antara penelitian ini dengan penelitian sebelumnya terletak pada teori fungsi perpustakaan. Jika pada penelitian Fuegi et al. (2011), penelitian Smith (2008) dan Rahmawati (2008) merujuk pada berbagai sumber yang menerangkan peran perpustakaan, maka penelitian ini bersumber pada teori fungsi perpustakaan yang dijelaskan oleh SulistyoBasuki (1991).

Perbedaan lain dengan penelitian Rahmawati (2008) yakni penelitian tersebut lebih menekankan pada teori persepsi, kelas sosial, lingkungan sosial dan gaya hidup, sedangkan pada penelitian ini peneliti berusaha memberikan penjelasan yang mendalam akan makna "fungsi perpustakaan" berdasarkan persepsi dari pemustaka yang berbeda latar belakang sosial.

\section{METODOLOGI PENELITIAN}

Penelitian ini menggunakan gabungan pendekatan kuantitatif dan kualitatif yang bersumber dari salah satu desain Creswell (2012) dalam Indrawan dan Yaniawati (2014: 81), yakni The Convergen Parallel Design atau yang lazim disebut Concurent Triangulation. Pendekatan kuantitatif pada penelitian ini dilakukan dengan metode survei deskriptif. Kuesioner dalam penelitian ini menggunakan pertanyaan tertutup dan terbuka. Pendekatan kualitatif dilakukan melalui observasi dan wawancara tidak terstruktur pada informan. Penelitian ini dilakukan di Perpustakaan Kota Yogyakarta. Populasi dalam penelitian ini 
adalah seluruh pemustaka di Perpustakaan Kota Yogyakarta. Sampel dalam penelitian ini dipilih menggunakan probability dengan cara simple random sampling dengan jumlah sebanyak 50 responden.

\section{HASIL DAN PEMBAHASAN}

1. Pengaruh Lingkungan Sosial Terhadap Persepsi pada Fungsi Perpustakaan

Pada bagian ini peneliti menguraikan siapa saja anggota dari lingkungan sosial yang mempengaruhi persepsi pemustaka terhadap fungsi perpustakaan dan bagaimana cara individu tersebut mempengaruhi persepsi.

a. Pengaruh Lingkungan Teman Sepermainan

Ajakan teman agar berkunjung ke perpustakaan sekolah untuk membaca buku dan mengerjakan tugas bersama membentuk persepsi siswa sekolah dan mahasiswa bahwa perpustakaan berfungsi sebagai tempat belajar. Persepsi juga terbentuk saat responden diajak teman untuk mengisi jam pelajaran yang kosong. Suasana yang tenang membuat pelajar merasa nyaman untuk menjadikan perpustakaan sebagai tempat pelarian yang positif saat pendidik berhalangan hadir di kelas. Anggapan perpustakaan sebagai tempat untuk cuci mata dialamatkan oleh salah satu siswa SMA karena pernah diberi saran oleh teman agar berkunjung ke perpustakaan karena bisa mengerjakan tugas sekaligus melihat cewek cantik.

b. Pengaruh Lingkungan Pendidik

Saran dari pendidik agar responden mengisi waktu luang di perpustakaan juga menjadi alasan tersendiri bagi responden akhirnya bersedia berkunjung ke perpustakaan. Tugas yang diberikan oleh guru dan dosen turut pula membentuk pandangan siswa bahwa perpustakaan adalah tempat yang menyediakan jawaban dari tugas, baik itu berupa buku, koran, CD (Compact Disk) tutorial maupun jurnal.

\section{c. Pengaruh Lingkungan Keluarga}

Anggapan dari anggota keluarga responden akan fungsi perpustakaan sebagai tempat untuk membaca buku, meminjam buku, menambah wawasan, mencari buku gratis dan untuk mengisi waktu luang diungkapkan oleh responden dengan status mahasiswa. Bentuk dukungan keluarga pada responden diploma 3 (D3) dan strata 1 (S1) sebatas pada saran untuk mengisi waktu luang dengan cara membaca buku di perpustakaan.

\section{Pengaruh Lingkungan Sosial Terhadap Kunjungan ke Perpustakaan}

Berdasarkan hasil analisis data, terdapat temuan bahwa lingkungan sosial tidak hanya berperan dalam persepsi terhadap fungsi perpustakaan, namun juga berpengaruh dalam motivasi pemustaka untuk datang ke perpustakaan. Ajakan teman untuk datang bersama menjadi motivasi tersendiri bagi pemustaka untuk mengerjakan tugas kelompok atau sekedar duduk santai di perpustakaan. Kalangan pendidik juga menjadi motivator bagi pemustaka dalam kunjungannya ke perpustakaan. Pelajar mengaku sering mendapat saran dari guru agar ke perpustakaan saat kesulitan menjawab tugas. Nasehat yang sama juga dirasakan oleh responden mahasiswa, sebab dosen juga selalu mengingatkan para mahasiswa agar melengkapi daftar pustaka dengan buku-buku dan jurnal dari perpustakaan.

Peran anggota keluarga menjadi motivator selanjutnya bagi pemustaka untuk berkunjung ke perpustakaan. Pelajar SMA dan mahasiswa mengaku bentuk dukungan dari keluarga hanya berupa nasehat dari orang tua agar mencari tambahan wawasan dan pengetahuan di perpustakaan. Sebagai orang yang merasa dirinya "lebih tua" diantara anggota keluarga yang lain, responden lulusan strata 2 (S2) justru berperan sebagai pihak yang mendorong anggota keluarga yang lain untuk berkunjung ke perpustakaan kota.

\section{Persepsi Pemustaka Terhadap Fungsi Perpustakaan}

Pada bagian ini peneliti akan menggambarkan persepsi pemustaka sesuai perbedaan stratifikasi sosial, yaitu stratifikasi pendidikan dan pekerjaan.

\section{a. Persepsi pada Fungsi Penyimpanan}

Pelajar dan mahasiswa mengatakan perpustakaan terlihat seperti gudang buku karena banyak buku yang hanya bertumpuk di rak, tetapi jarang digunakan. 
Keanekaragaman jenis buku dari segala bidang ilmu juga menimbulkan kesan perpustakaan seperti gudang buku. Diluar anggapan perpustakaan sebagai gudang buku, terdapat pula pelajar dan mahasiswa yang mengungkapkan perpustakaan sebagai gudang informasi dan ilmu pengetahuan. Pengalaman pelajar yang telah mengunjungi Perpustakaan Kota Yogyakarta juga membuat responden memandang bahwa perpustakaan bukanlah gudang buku sebab memiliki bangunan yang bagus, tidak mirip sebuah gudang. Responden lulusan S1 menyatakan tidak sependapat bila perpustakaan diartikan sebagai gudang buku dengan alasan perpustakaan di era modern seperti saat ini sudah memiliki internet. Responden lulusan S2 memberikan saran tambahan koleksi agar perpustakaan tidak lagi menjadi gudang buku, seperti CD tentang pemandangan alam dari berbagai daerah, seni musik, seni tari, cara hidup masyarakat pedalaman hingga film tentang perjuangan dan pendidikan di Indonesia.

Keinginan pelajar untuk dapat melihat koleksi perpustakaan sekolah yang tidak hanya berbentuk buku juga akan terwujud jika perpustakaan berhasil menyalin buku menjadi digital. Pandangan yang berbeda disampaikan oleh mahasiswa. Mahasiswa D3 beranggapan bahwa buku tua perlu dilestarikan karena merupakan cikal bakal lahirnya buku baru dengan tema sejenis, termasuk edisi revisi. Mahasiswa S1 menganggap digitalisasi berguna untuk antisipasi atau cadangan. Mahasiswa S2 memberikan batasan duplikasi koleksi dapat dilakukan hanya untuk tujuan penelitian dan pendidikan. Manfaat lain dari digitalisasi koleksi diungkapkan oleh responden yang bekerja sebagai pegawai negeri sipil, bahwa kegiatan tersebut dapat membantu pelestarian kebudayaan daerah. Seorang dosen menyatakan koleksi dalam bentuk digital memberikan banyak keuntungan, selain memudahkan pencarian, koleksi digital juga bebas rayap, hemat tempat dan mudah dalam perawatan.

\section{b. Persepsi pada Fungsi Informasi}

Impian siswa SMA agar perpustakaan terlihat modern, yakni dengan penggunaan perangkat teknologi juga menjadi faktor pendorong tersendiri bagi responden menyatakan setuju jika perpustakaan menambahkan layanan informasi dalam bentuk digital. Bagi siswa SMA, adanya internet di perpustakaan akan merubah perpustakaan menjadi tempat yang tidak ketinggalan zaman. Meski menghendaki adanya internet di perpustakaan, pelajar SMA memastikan tidak akan menggunakan internet untuk mencari halhal yang tidak baik, seperti pornografi. Siswa SMP yang juga menimba ilmu di pesantren beranggapan bahwa perpustakaan merupakan gudang informasi dan ilmu pengetahuan.

Mahasiswa menyatakan, gabungan layanan informasi dalam bentuk manual dan digital akan memberikan manfaat saling melengkapi. Jika terjadi gangguan teknis seperti mati listrik atau gangguan koneksi internet, maka layanan manual akan menjadi alternatif dalam mencari informasi di sebuah perpustakaan. Namun demikian, ada pula mahasiswa yang menyatakan lebih senang dengan layanan manual.

\section{c. Persepsi pada Fungsi Rekreasi}

Menurut mahasiswa D3 dan S1, program liburan di perpustakaan kota akan memberikan pengaruh pendidikan bagi kegiatan tersebut. Liburan di perpustakaan merupakan ajang piknik yang mendidik. Keinginan mahasiswa pada program liburan di perpustakaan juga beragam, seperti nonton film, belajar bersama di alam terbuka, diskusi dengan tokoh penting, bazar buku dan sumbang buku ke pelosok desa.

Saat menyatakan setuju dengan program nonton film, pelajar memberikan alasan bahwa belajar sejarah atau science dalam bentuk film terasa lebih mudah dipahami dibandingkan hanya dengan membaca buku. Sambutan baik dari pelajar saat menanggapi program nonton film di perpustakaan kota juga terlihat dari beragamnya usulan judul film yang ingin disaksikan. Siswa SMP ingin melihat film sejarah asal usul manusia, luar angkasa dan sejarah terbentuknya Indonesia, sedangkan siswa SMA menginginkan film kartun lucu, tata surya dan dinosaurus. 
Pelajar mengungkapkan, fasilitas tempat "nongkrong" dan cafee di perpustakaan merupakan hal yang sangat dinantikan karena akan membuat suasana belajar menjadi lebih santai. Pandangan yang berbeda pada fasilitas "kongkow" di perpustakaan disampaikan oleh mahasiswa. Kesan sumber pengetahuan yang melekat pada diri perpustakaan memunculkan anggapan bahwa nongkrong di perpustakaan adalah nongkrong yang positif, karena orang yang memilih "nongkrong" di perpustakaan pastilah orang yang berpendidikan. Hal yang sama juga tersirat dalam pernyataan Achmad et al. (2012: 29) "Bersosialisasi di perpustakaan mempunyai nilai tersendiri. Perpustakaan merupakan tempat terhormat. Pertemuan di perpustakaan mempunyai citra yang lebih baik bila dibanding dengan pertemuan di jalan, mall dan lain-lain"

\section{d. Persepsi pada Fungsi Pendidikan}

Kesadaran mahasiswa yang memandang bahwa di perpustakaan terdapat berbagai hal yang dapat dijadikan objek penelitian, menjadikan mahasiswa setuju jika ada pihak tertentu yang ingin meneliti perpustakaan. Lebih dalam mahasiswa D3 dan S1 menjelaskan, bagian dari perpustakaan yang dapat diteliti seperti koleksi buku yang tua dan lapuk, petugas yang terkesan kaku serta gedung yang terlihat suram. Mahasiswa S2 menjelaskan bahwa jenis layanan dan penggunaan teknologi di perpustakaan dapat menjadi objek penelitian yang menarik. Mahasiswa dan lulusan perguruan tinggi juga samasama menyatakan bahwa perpustakaan justru menjadi pihak yang membantu suksesnya kegiatan penelitian seseorang, yakni melalui koleksi dan layanan yang ada.

Beragam ide diberikan oleh responden pada pelaksanaan kegiatan berbagi buku dengan sesama. Siswa SMA menyarankan sumbangan buku diberikan kepada sekolahan yang tidak memiliki perpustakaan dan panti asuhan. Mahasiswa menghendaki agar buku didonasikan kepada masyarakat masyarakat pelosok desa yang tidak mampu membeli buku, belum memiliki perpustakaan desa, orang- orang yang habis tertimpa bencana, masyarakat yang minim sekolahan, kumpulan anak-anak jalanan, atau ke pelosok desa yang belum memiliki toko buku. Mahasiswa S2 menyampaikan ide agar buku disalurkan kepada masyarakat dengan minat baca rendah. Responden berharap, masyarakat akan mulai menyukai kegiatan membaca setelah mendapat bantuan buku gratis.

\section{e. Persepsi pada Fungsi Kultural}

Bagi mahasiswa S1 kegiatan seminar bermanfaat untuk ajang promosi gratis akan keberadaan perpustakaan. Lebih jauh mahasiswa S1 menjelaskan, meski awalnya masyarakat datang ke perpustakaan untuk tujuan seminar, tidak menutup kemungkinan kelak masyarakat tersebut akan datang ke perpustakaan untuk membaca atau meminjam buku. Seorang dosen memberikan batasan jika untuk tujuan memperkenalkan kebudayaan bangsa maka seminar dapat diadakan disebuah perpustakaan kota.

Sisi positif kegiatan story telling dan story reading di perpustakaan disampaikan oleh seorang guru, bahwa aktivitas anakanak yang kurang baik seperti berkelahi dengan teman atau jalan-jalan ke mall dapat dikurangi dengan kegiatan latihan mengarang cerita atau lomba menulis cerpen. Satu ide diberikan oleh responden yang bekerja sebagai guru, yakni lomba bercerita menggunakan bahasa Jawa. Rasa miris pada kenyataan makin banyaknya anak-anak yang gemar menggunakan gadget, membuat dosen menaruh harapan besar bahwa kegiatan story telling dan story reading dapat menjadi hal yang akan mampu mengalihkan perhatian anak agar tidak selalu tertuju pada game online. Seorang ibu rumah tangga berharap, adanya kegiatan story telling dan story reading dapat mengembalikan semangat gemar membaca pada anak-anak.

Mahasiswa D3, S1 dan S2 juga berkenan memberikan ide kreativitas yang sesuai bagi anak-anak, seperti bermain wayang, merangkai bunga, menghias telur dan membatik saputangan. Menurut responden lulusan S1, tersedianya fasilitas untuk pengembangan kreativitas dan bakat anak dalam bidang seni merupakan 
terobosan yang baru dalam dunia perpustakaan. Perpustakaan telah keluar dari zona aman yang hanya terpaku pada aktivitas yang berkaitan dengan buku.

\section{E. KESIMPULAN}

Setelah melakukan analisis data dapat disimpulkan bahwa lingkungan sosial (teman sepermainan, keluarga dan pendidik) berpengaruh dalam membentuk persepsi pemustaka di Perpustakaan Kota Yogyakarta. Pemustaka memandang perpustakaan menjadi multifungsi, tidak hanya sebagai gudang buku atau sebagai tempat belajar, namun juga sebagai tempat untuk menambah wawasan, tempat bermain bersama teman, bermain dengan keluarga hingga tempat untuk cuci mata. Peneliti juga mendapatkan temuan bahwa lingkungan sosial juga berperan dalam mendorong pelajar, mahasiswa dan lulusan S1 untuk berkunjung ke perpustakaan.

Kesadaran akan pentingnya kandungan informasi dari buku tua dan sulit dicari, membuat pemustaka baik pelajar, mahasiswa hingga lulusan perguruan tinggi mempersepsi bahwa perpustakaan merupakan lembaga pelestari koleksi langka. Tersedianya fasilitas area gazebo di Perpustakaan Kota Yogyakarta lengkap dengan wifi gratis membentuk persepsi pemustaka (pelajar dan mahasiswa) bahwa perpustakaan dapat menjadi tempat untuk nongkrong bersama teman. Kegiatan liburan dan lomba menulis cerpen yang diadakan di Perpustakaan Kota Yogyakarta menjadikan responden beranggapan bahwa perpustakaan dapat menjadi pilihan tempat untuk mengisi liburan.

Keyakinan dari dalam diri responden bahwa perpustakaan kota memang didirikan untuk tujuan mencerdaskan seluruh lapisan masyarakat, membuat responden memandang bahwa perpustakaan adalah tempat belajar bagi siapa saja yang membutuhkan. Selain itu, perpustakaan juga berfungsi sebagai tempat untuk bermain dan belajar yang positif bagi anak-anak, sehingga anak-anak tidak lagi senang ke mall, ketergantungan dengan gadget atau tawuran di jalanan.

\section{DAFTAR PUSTAKA}

Davis, C. H. and Shaw, D., 2011, Introduction to Information Science and Technology, New Jersey: Information Today, Inc.
Hunt, E. F. and Colander, D. C., 1996, Social Science: An Introduction to the Study of Society, Massachusetts: Allyn \& Bacon.

Indrawan, R. dan Yaniawati, R. P., 2014, Metodologi Penelitian: Kuantitatif, Kualitatif, dan Campuran untuk Manajemen, Pembangunan dan Pendidikan, Bandung: Refika Aditama.

Schaefer, R.T., 2013, Sociology: A Brief Introduction, 10th edition, New York: McGraw-Hill.

Sobur, A., 2013, Psikologi Umum: dalam Lintasan Sejarah, Bandung: Pustaka Setia.

Soekanto, S., 1999, Sosiologi: Suatu Pengantar, Jakarta: Raja Grafindo Persada.

Sulistyo-Basuki, S., 1991, Pengantar Ilmu Perpustakaan, Jakarta: Gramedia.

Sunarto, K., 1993, Pengantar Sosiologi, Jakarta: Lembaga Penerbit Fakultas Ekonomi Universitas Indonesia.

Suwarno, W., 2010, Ilmu Perpustakaan dan Kode Etik Pustakawan, Jogjakarta: Ar-Ruzz Media.

Thoha, M., 1995, Perilaku Organisasi: Konsep Dasar dan aplikasinya, Jakarta: RajaGrafindo Persada.

\section{JURNAL ELEKTRONIK:}

Fuegi, D., Segbert-Elbert, M., and Lipeikaite, U., 2011, Public libraries in Africa-agents for development and innovation? Current Perceptions of local stakeholders, (internet), $<$ http://conference.ifla.org/pastwlic/2011/183-fuegi-en.pdf $>$ (diakses 24 Juni 2014).

\section{TESIS DAN DISERTASI:}

Rahmawati, R., 2008, Persepsi Masyarakat Terhadap Keberadaan Perpustakaan: Studi Tentang Perpustakaan Daerah Istimewa Yogyakarta, Tesis: Universitas Gajah Mada.

Smith, S., 2008, Working Librarians' Perceptions of The Role of The Public Library In The 21st Century, Dissertation: The University of Texas At Arlington, <http://search. proquest.com.ezproxy.ugm.ac.id/dissertati ons/docview/304825861/7C21CAF77A14 B25PQ/8?accountid=13771> (diakses 9 Februari 2014). 